\title{
Portal de Informações Gerenciais: a inteligência informacional como instrumento de governança do Plano Rio Sem Miséria
}

1 Superintendente de Renda de Cidadania da Secretaria de Assistência Social e Direitos Humanos do Estado do Rio de Janeiro.

2 Subsecretário de Integração de Programas Sociais da Secretaria de Assistência Social e Direitos Humanos do Estado do Rio de Janeiro.

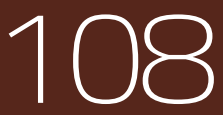

Em alinhamento com as diretrizes do Plano Brasil sem Miséria, do Governo Federal, o Governo do Estado do Rio de Janeiro instituiu o Plano Rio sem Miséria ${ }^{3}$ - (RSM), com o objetivo de erradicar a pobreza extrema no Estado e tendo como premissas a multidimensionalidade da pobreza e a necessária articulação federativa para sua superação.

Dada a complexidade das estratégias para a superação da pobreza e o fato de a informação ser um insumo estratégico para a formulação e gestão dessas ações, especialmente as relacionadas à articulação intersetorial e ao relacionamento com os municípios, a Secretaria de Assistência Social e Direitos Humanos (SEASDH) estabeleceu parceria com o Centro de Tecnologia da Informação e Comunicação do Estado do Rio de Janeiro (PRODERJ) visando à elaboração de um plano estratégico para o desenvolvimento de siste- mas de informação - tanto gerenciais quanto transacionais, para o acompanhamento, operacionalização, monitoramento e transparência das ações em curso.

O Rio sem Miséria possui os seguintes objetivos específicos: (i) aumentar a renda das famílias extremamente pobres para além do nível de extrema pobreza, por meio da transferência de renda realizada às famílias com o Programa Renda Melhor; (ii) incentivar a permanência e a conclusão com qualidade do ensino médio dos jovens de famílias beneficiárias do Renda Melhor mediante a concessão de prêmios financeiros, diretamente ao jovem, depositados em conta poupança via o Programa Renda Melhor Jovem e (iii) ampliar a inclusão social da população de baixa renda, articulando suas capacidades e potencialidades às oportunidades econômicas e sociais. 
Os municípios também assumem lugar de destaque no RiosSem Miséria, posto que somente por meio de uma maior proximidade com as famílias que moram no território é possível identificar suas potencialidades e vulnerabilidades e construir um plano de desenvolvimento para as famílias que permita superar a extrema pobreza. Além disso, os municípios são responsáveis pela coleta e atualização das informações do Cadastro Único para Programas Sociais do Governo Federal (CADÚNICO).

\section{Portal de Informações Gerenciais do Rio Sem Miséria}

No início de 2011, a Base do Cadastro Único não era utilizada de forma sistemática por nenhuma área do Governo do Estado do Rio de Janeiro para a formulação, implementação, monitoramento e avaliação de políticas ou programas. A decisão de utilizar as informações do CADÚNICO como insumo para a execução do Plano Rio sem Miséria, seja para a apuração da renda estimada ou para ações prioritárias de busca ativa - demandou a formulação de um plano no qual a tecnologia da informação assumiu lugar de destaque.

O plano compreende diversos sistemas de natureza transacional e gerencial. No eixo dos sistemas transacionais foram desenvolvidos os sistemas de gestão do Renda Melhor, Renda Melhor Jovem e de Consulta à base estadual do Cadastro Único. No segmento gerencial, insere-se o Portal RSM e a previsão de desenvolvimento de um portal de acesso público para disponibilização de informações sobre o Rio Sem Miséria para a sociedade em geral.

O aplicativo de monitoramento do Plano Rio sem Miséria, denominado Portal de Informações Gerenciais do Rio sem Miséria (Portal RSM), disponibiliza informações essenciais para a implementação e gestão do Plano e, ao mesmo tempo, é o instrumento que permite o compartilhamento das informações com todos os municípios e órgãos de Governo que necessitem utilizá-las para formulação de políticas públicas direcionadas às famílias em extrema pobreza e pobreza.

O Portal RiosSem Miséria foi desenvolvido empregando os conceitos e tecnologia de Business Intelligence (BI), e para sua implantação o PRODERJ alocou os seguintes recursos tecnológicos: Microsoft SharePoint (em dois servidores de aplicação em Loadbalance); SAP Business Object Enterprise (em um servidor de aplicação), Microsoft SQL 2008 (em dois Servidores de Banco de Dados em cluster), operando em ambiente Windows. 


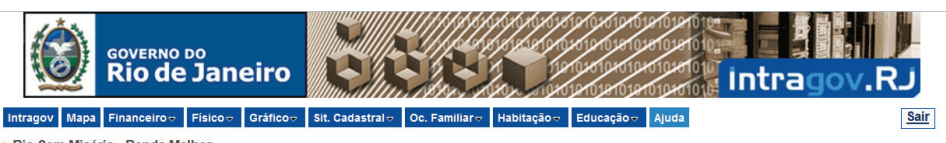

pRio Sem Miséria - Renda Melhor

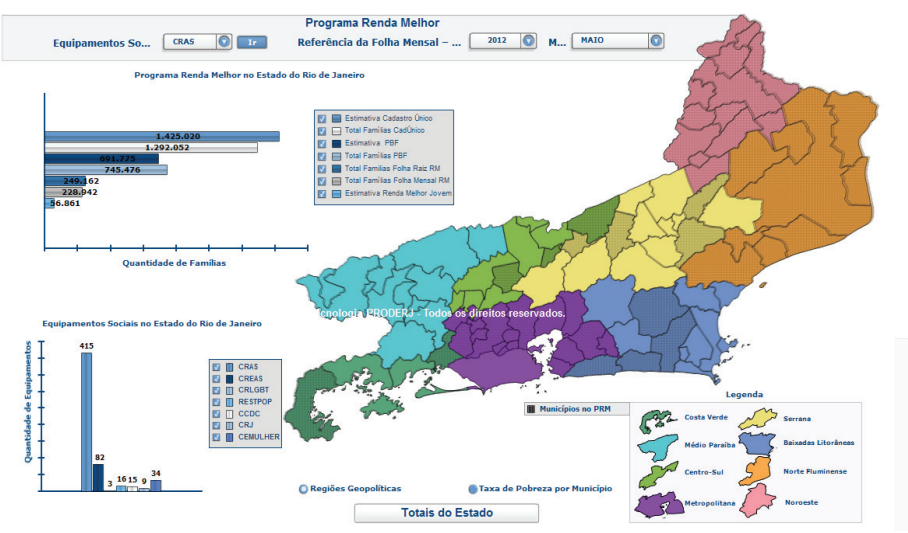

Por se tratar de uma ferramenta de natureza gerencia, e que tem por público-alvo o nível estratégico da esfera estadual e municipal, foi criada uma interface intuitiva e de fácil utilização na qual são disponibilizados relatórios e painéis de controle sobre as políticas sociais e respectivas ações dos programas no âmbito dos 92 municípios do Estado do Rio de Janeiro. Foi concebido de forma modular e atualmente possui os seguintes módulos, todos com acesso via internet, que auxiliam a SEASDH na gestão e acompanhamento do Plano Rio Sem Miséria:

i) Módulo do Cadastro Único - tem como objetivo caracterizar o perfil das famílias de baixa renda de cada município do Estado do RJ e balizar as ações de busca ativa para inclusão no CADÚNICO de segmentos mais vulneráveis, comoCcatadores deMmaterial Reciclável e Quilombolas. Em seus relatórios é possível visualizar as informações por diferentes recortes: raça/ Cor, gênero, faixa etária, escolaridade por faixa etária, ocupação familiar, famílias com deficientes, indígenas e quilombolas, pessoas sem registro civil, e também informações sobre as características dos domicílios - como, por exemplo, urbana/ rural, coletivo/particular, quantidade de cômodos, tipo de iluminação, escoamento sanitário, entre outros.

ii) Módulo do Renda Melhor - visa apresentar o perfil das famílias beneficiárias do Programa Renda Melhor por meio de relatórios e gráficos de evolução semelhantes aos existentes no módulo do Cadastro Único. Permite, ainda, acompanhar o pagamento dos benefícios às famílias por meio de relatórios que disponibilizam comparativos físico e financeiro.

No painel de controle deste módulo, é exibido o mapa do Estado do Rio de Janeiro 
(ver figura 3) apresentando a taxa de extrema pobreza, segundo ocCenso de 2010, de cada um dos municípios do Estado que, quando selecionado, apresenta as estimativas e quantidades totais de famílias no Cadastro Único, no Programa Renda Melhor, no Programa Renda Melhor Jovem, além da relação dos equipamentos sociais existentes (CRAS, CREAS, Centros de Referência da Juventude e da Mulher, Centros LGBT, Restaurantes Populares, entre outros).

iii) Módulo do Renda Melhor Jovem - tem como objetivo acompanhar o Programa Renda Melhor Jovem, que é uma poupança destinada aos jovens integrantes das famílias do Programa Renda Melhor. Neste módulo, são disponibilizados relatórios e gráficos demonstrando os totais de Jovens por série e respectivos prêmios pagos.

iv) Módulo do Bolsa Família - tem como objetivo o acompanhamento do Programa Bolsa Família (PBF) no Estado do RJ. Informações sobre estimativas e valores reais de atendimento às famílias são apresentadas por meio de relatórios e gráficos.

Todos os relatórios disponibilizados nos módulos do Cadastro Único e do Renda Melhor podem ser visualizados por diferentes filtros de renda: 3 salários mínimos de renda familiar, $1 / 2$ salário mínimo per capita (perfil do Cadastro Único), 1/4 de salário mínimo per capita, $\mathrm{R} \$$ 140,00 per capita (perfil Bolsa Família), R\$ 70,00 per capita (perfil Brasil Sem Miséria), renda R\$100 e renda zero. São disponibilizados, também, gráficos que permitem acompanhar, por exemplo, a evolução da "Cobertura" do Cadastro Único no estado do Rio de Janeiro.

O Portal RSM foi lançado em junho de 2012 contemplando a série histórica das bases do CADÚNICO e das folhas de pagamento do PBF e do RSM a partir de setembro de 2011. Com a sua implantação, foi possível elaborar um diagnóstico socioeconômico sobre a situação de cada um dos 92 municípios no que diz respeito à gestão do Cadastro Único, do PBF e do Renda Melhor. A partir desse diagnóstico, a SEASDH realizou articulações e forneceu apoio técnico aos municípios para a execução de diversas ações com vistas à ampliação da cobertura cadastral e a realização de busca ativa de famílias em extrema pobreza para a inclusão no CADÚNICO, de modo a viabilizar o acesso a programas e serviços socioassistenciais.

No período de setembro de 2012 a dezembro de 2012 foi realizado um piloto com 11 municípios ${ }^{4}$ com o objetivo de avaliar e validar o conjunto de relatórios e gráficos já disponibilizados, bem como colher sugestões e propostas para o aprimoramento do Portal. Finalizado o piloto, a Secretaria Estadual de Assistência Social e Direitos Humanos iniciou em maio de

4 Participaram do piloto os seguintes municípios: Belford Roxo, Cabo Frio, Campos dos Goytacazes, Duque de Caxias, Itaguaí, Japeri, Magé, Piraí, Quissamã, Rio de Janeiro e São Gonçalo.

Revista Brasileira de Monitoramento e Avaliação | Número 6 | Julho-Dezembro de 2013 


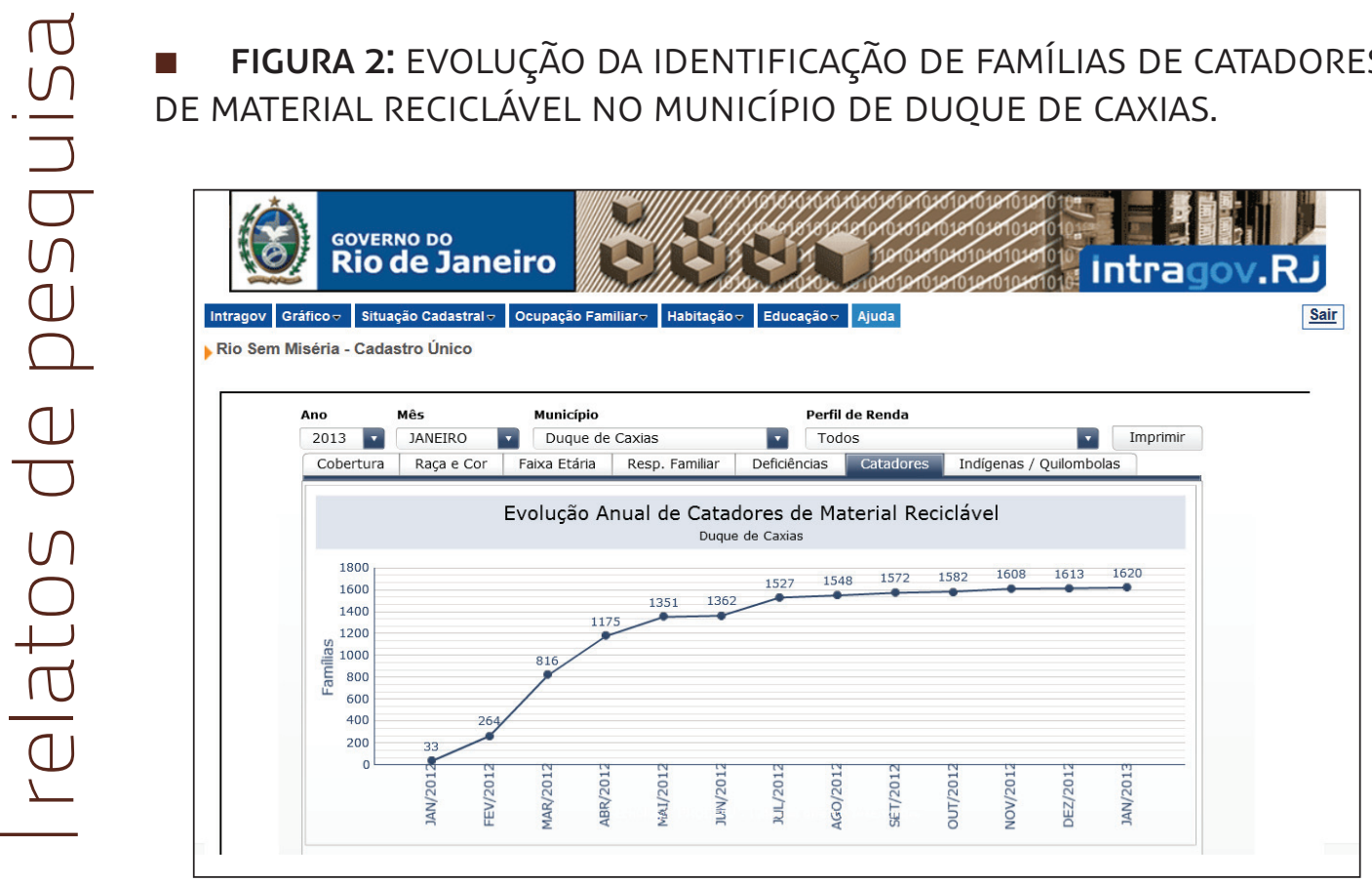

2013 a disponibilização do acesso para os demais 81 municípios do Estado. Foram realizadas duas oficinas, com a participação de secretários municipais e coordenadores municipais do PBF/ CADÚNICO, de modo a apresentar a ferramenta e os procedimentos operacionais para a viabilização do acesso.

O Portal é atualizado mensalmente e tem como fontes de informação, além da base estadual do CADÚNICO, a base anual do Censo SUAS, as folhas de pagamento do Programa Bolsa Família e do Programa Renda Melhor e as informações oriundas dos sistemas de Gestão dos programas Renda Melhor e Renda Melhor Jovem.

Dentre as principais ações, destaca-se a inclusão/identificação de famílias integrantes de segmentos específicos e his- toricamente não atendidos pelas políticas sociais, como catadores de material reciclável e Quilombolas. Nesse sentido, foram realizadas diversas ações em conjunto com os municípios com vistas à inclusão/ identificação de famílias de catadores de material reciclável nos Aterros de Jardim Gramacho (Duque de Caxias) e Itaoca (São Gonçalo).

A seguir, exemplificamos algumas das potencialidades de utilização de informações para o monitoramento das ações realizadas.

A Figura 2 permite aferir o esforço de busca ativa de famílias de catadores de material reciclável empreendido antes do fechamento do aterro sanitário de Jardim Gramacho, ocorrido em junho de 2012, no município de Duque de Caxias. 


\section{- figura 3: evolução da cobertura do renda melhor DESAGREGADA POR RAÇA/COR.}

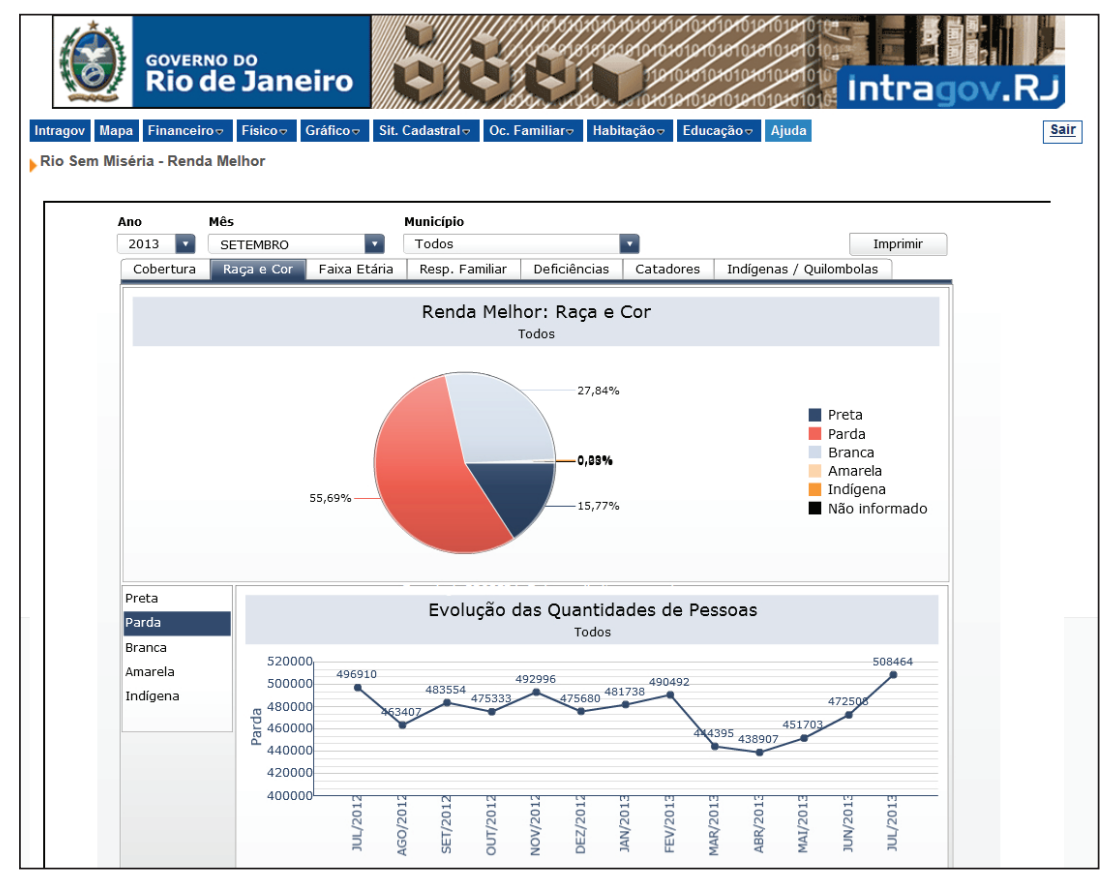

Outro exemplo refere-se à evolução da cobertura do Renda Melhor por raça e cor, onde se percebe a predominância da população negra (pretos e pardos), em consonância com o perfil da pobreza extrema no estado do Rio de Janeiro.

\section{Conclusão}

A implantação do Portal RSM foi de fundamental importância para lidar com os desafios de gestão e monitoramento de um plano com a escala atingida pelo Rio sem Miséria, que hoje já está implantado em todos os municípios do Estado e beneficiando diretamenta mais de 1,2 milhão de pessoas.

Cabe destacar alguns elementos importantes a serem analisados no âmbito da gestão pública. A institucionalização dos processos de execução e monitoramento pela via da parceria com o Centro de Tecnologia da Informação e Comunicação do Estado do Rio de Janeiro (PRODERJ) se constitui um fator positivo que permitirá a 
sustentabilidade do processo e fortalece a integração intrainstitucional. No âmbito dessa integração, vale sublinhar a transferência de conhecimento da SEASDH ao PRODER] sobre as bases de dados e conceitos referentes ao Cadastro Único, Bolsa Família e outras tecnologias sociais. Essa solução apresenta grande potencial de replicabilidade, posto ter sido desenvolvida por um órgão público e ter possibilidade tecnológica e institucional de ser compartilhada com outros entes da federação.

Outro aspecto vital é o processo de fomento, junto aos municípios do Estado do Rio de Janeiro, de uma prática efetiva de análise e elaboração de diagnósticos que permitm aumentar a eficiência e a transparência da gestão de políticas públicas. Esseoé o principal desafio a ser enfrentado. Em que pese a estratégia de desenvolver uma solução com uma interface simples e amigável, de modo que os profissionais e gestores municipais possam utilizá-la sem que seja necessário um processo específico de capacitação, a barreira a ser vencida reside na necessidade de estimular a prática do uso intensivo de ferramentas dessa naturez, não somente por parte dos técnicos e assessores, mas sobretudo pelos próprios gestores responsáveis pela condução das políticas sociais. E isso pode ser observado a partir de alguns relatos de secretários municipais após a realização das oficinas de apresentação da ferramenta: 
"Com esse portal, poderemos fazer um acompanhamento e a vigilância de políticas públicas por meio de uma análise de dados. Com isso será possível mapear ações mais específicas para desenvolver soluções para os possíveis problemas. Através dele, a gente pode ver o problema social de perto."

(Secretária de município da Região Metropolitana)

"O que eu acho é que nós vamos ter um diagnóstico mais apurado para planejar e para sanar problemas que a população já tenha e a gente desconheça. Pela apresentação eu acho que o manuseio será fácil e ajudará muito no meu trabalho."

(Secretária de município da Região da Costa Verde)
Ao propiciar o acesso a informações gerenciais pelo Estado do RJ e pelos municípios,Oo Portal de Informações Gerenciais do Plano Rio sem Miséri é um importante instrumento para o planejamento, a implementação e o monitoramento de ações integradas voltadas à população em situação de vulnerabilidade social. Além disso, os resultados positivos alcançados por um determinado município acabam por estimular outros municípios a empreenderem ações visando ao aprimoramento de sua gestão. O Portal se configura, assim, um potente instrumento para disseminar a prática do uso sistemático de informações gerenciais pelos agentes públicos-- um fator essencial para o aprimoramento da gestão das políticas sociais. 